Author version: Nat. Hazards, vol.61; 2012; 1007-1028

\title{
Return period estimates of extreme sea level along the east coast of India from numerical simulations
}

\author{
B. Sindhu* and A. S. Unnikrishnan \\ National Institute of Oceanography, Council of Scientific and Industrial Research \\ Dona Paula, Goa, 403004, India \\ Present affiliations: COWI Gulf A/S \\ Dubai, UAE, PO Box 52978
}

\begin{abstract}
Estimates of return periods of extreme sea level events along the coast are useful for impact assessment. In this study, a vertically integrated 2D model was developed for the simulation of storm surges in the Bay of Bengal. The bathymetry for the model was derived from an improved ETOPO-5 dataset, which was prepared in our earlier work. The meteorological forcing for the model was obtained from the cyclone model of Holland using the data available for 136 low pressure systems (LPS) that occurred during 1974-2000 in the Bay of Bengal. The simulated total sea level and the surge component were obtained for each event. The simulated peak levels showed good agreement with the observations available at few stations. The annual maxima of sea levels, extracted from the simulations, were fitted with Gumbel distribution using r-largest annual maxima method to estimate the 5-year and 50-year return periods of extreme events at 26 stations along the east coast of India. The return periods estimated from simulated sea levels showed good agreement with those obtained from observations. The 5-year and 50-year return levels of total sea level along the east coast of India show a considerable increase from south to north, with the 50year return total sea levels being as high as $6.9 \mathrm{~m}$ and $8.7 \mathrm{~m}$ at stations along the north eastern coast such as Sagar Island and Chandipur, respectively. The high return levels are expected at these stations as the cyclones developed in the Bay of Bengal generally move north or north-west, producing extreme events in the northern part and moreover, these stations are characterized by high tidal ranges. However, at some regions in the southern part such as Surya Lanka and Machilipatnam, though 50-year return levels of total sea-level are not very high (2.98 m and 2.97 $\mathrm{m}$, respectively) because of the relatively lower tidal ranges, high return levels of surges $(0.84 \mathrm{~m}$ and $0.57 \mathrm{~m}$, respectively) are found. In addition to the role of shallow bathymetry $(-5.0 \mathrm{~m}$ and 6.1 $\mathrm{m}$, respectively) at the two stations, the high return levels of surges are attributed to the effect of geometrical configuration at Surya Lanka and width and orientation of continental shelf $(100 \mathrm{~km})$ at Machilipatnam.
\end{abstract}

Keywords: Extreme events, return periods, storm surges, numerical simulation, Bay of Bengal.

\author{
*Corresponding author \\ e-mail: sindhumol123@gmail.com (BSindhu) \\ unni@nio.org (A.S Unnikrishnan)
}




\section{Introduction}

The massive destruction and loss of human life associated with a tropical cyclone can be attributed mainly to the sudden inundation and flooding of the coastal areas produced by storm surges. Though the cyclones generated in the Indian Ocean are weaker and smaller than those generated in Pacific and Atlantic Ocean, the death toll is highest. According to Frank and Hussain (1971), there were a total of 9-recorded cases of heavy human loss over past 300 years, in which 7 (77\%) cases occurred in Indian subcontinent. This can be attributed to the high population, approximately 63 and 62 million, settled in the Low Elevation Coastal Zones (LECZ) of India and Bangladesh, respectively which are at higher risks of flooding during cyclonic events (McGranahan et al. 2007). In the northern Indian Ocean, there are 5-6 times more tropical disturbances in the Bay of Bengal than in the Arabian Sea (Dube et al. 1997). The tropical cyclones formed in the Bay of Bengal usually move toward west, north west or north before finally curving east into north-east corner of the bay, affecting the east coast of India, Bangladesh, Myanmar and Sri Lanka. The extent of damage at the coast was documented in many earlier studies (Murty et al. 1986; Dube et al. 2000). The most disastrous destruction often results when an extreme storm surge event occurs in conjunction with high tides, for example, during Bangladesh cyclone in 1970, the peak surge coincided with high tide killing more than 200000 people. Whereas a comparable surge on 31 October 1960 occurred at low tide and hence was far less destructive (Murty et al. 1986). Thus real time monitoring and warning of storm surges are of great concern.

During the last few decades, much effort has been directed to the modelling of storm surges generated by intense cyclonic systems in the Bay of Bengal. Das (1972) pioneered the study of numerical storm surge modelling in India. Subsequently several workers attempted the simulation of storm surge in the Bay of Bengal (Ghosh 1977; Johns and Ali 1980; Johns et al. 1981; Dube et al. 1985; Johns et al. 1985; Dube and Gaur 1995), which have been extensively reviewed by Murty et al. (1986). Flather (1994) applied a model with 1D equations for narrow channels and 2D equations for the open sea to the northern Bay of Bengal including the coast of Bangladesh to simulate the surge due to April 1991 cyclone. In the last decade, only a few attempts have been done (Jain et al. 2007; Dube et al. 2006) to develop large scale storm surge models for the Bay of Bengal, with most of the works on location specific high resolution models. Dube et al. (2009) summarized the recent development in storm surge prediction systems that have been successfully applied in Bay of Bengal and Arabian Sea. They also carried out simulation of storm surges caused due to some recent severe cyclonic events such as Male (2006), Gonu (2007), Sudr (2007) and Nargis (2008) that hit different coast bordering Bay of Bengal.

A few region-specific real time numerical surge models have been developed to study the impact of cyclonic events along the coast of different countries in Bay of Bengal such as Bangladesh (Jackobsen et al, 2006), Myanmar (Sinha et al. 2005; Jain et al 2006a) and Sri Lanka (Chittibabu et al. 2002). A large number of location specific high resolution models have been developed and successfully applied to the maritime states along the east coast of India such as Chittibabu et al. (2002) (Tamil Nadu), Dube et al. (2000b) (Andhra Pradesh), Dube et al. (2000a, b) and Sinha et al. (2008) (Orissa), Dube et al. (2004) (head bay).

The domains of the above mentioned localized models are confined to the vicinity of the 
coastal areas. Moreover, most of the storm surge models are location specific or developed to simulate individual storm surge events. Therefore, in the present study, a large scale model has been developed to study the impacts of different cyclonic events for the entire stretch of eastern coast of India.

In addition, so far, there have been few attempts to make a quantitative estimate of the return periods of storm surges along the east coast of India by analysing large number of cyclone events. Chittibabu et al. (2004) estimated return periods of storm surges along the coast of Orissa based on model results. Jakobsen et al. (2006) carried out statistical analysis of the numerically simulated surge heights due to severe cyclonic events that hit the coast of Bangladesh from 1960-2000 in order to estimate the 100 year return period of extreme sea level. Unnikrishnan et al. (2004) analysed the hourly tide gauge data at three stations, Paradip, Visakhapatnam, and Chennai, for a period of 15 years (1974-1988) and estimated the 100-year return level for these stations. The availability of tide gauge data only at 4-5 locations along the east coast of India and the rare occurrence of cyclone at a given tide gauge location, however, make the direct analysis of observational data very difficult. Moreover, during some of the intense cyclonic events, tidegauges became non-functional. Consequently, there arises the necessity to use the numerically simulated storm surges for the analysis of the extreme events in the regions where the tide gauge data are not available. Unnikrishnan et al (2011) compared the 100-year return levels estimated from statistical analysis of storm surges simulated for a base line scenario (1961-1990) and a future A2 scenario (2071-2100), forced by winds and sea-level atmospheric pressure from PRECIS (Providing REgional Climates for Impacts Studies) regional climate model and imposed by a future sea-level rise. They found an increase in the 100-year return levels of extreme sea level events by about $15-20 \%$ for the latter scenario for stations north of Visakhapatnam.

In the present work, we developed a 2D non-linear numerical model for simulating storm surges caused by different low pressure systems that were identified during the past 27 years (1974-2000) in the Bay of Bengal. We analysed the total sea level and surge levels simulated for the cyclonic events in the 27 years and estimated the return periods and return levels of extreme events at 26 stations along the east coast of India. Though the region of interest includes the entire Bay of Bengal, we concentrated on the results along the east coast of India.

Similar work has been carried out by Jain et al (2010), who estimated the expected total water level for each coastal district of the maritime states along the east coast of India. However, the methodology followed by Jain et al (2010) is slightly different from the present study as they have carried out storm surge simulations for synthetic cyclonic events developed from statistically projected cyclone intensities based on the analysis of historical data. The major improvement of the present study over Jain et al (2010) is the inclusion of the atmospheric forcing and tidal forcing simultaneously in the model in order to allow for tide-surge interaction. The non-linear interaction between tides and surge and its substantial impact on the resultant surge height have been studied by Horsbugh et al. (2007), Butler et al (2006), Johns et al. (1985) and emphasized in several earlier works as a step of improvement required for accurate assessment of total water level.

The outline of the paper is as follows. A description of the models used to generate cyclone and storm surge and their application to Bay of Bengal are given in section 2. The model 
validation using the observed hourly sea level is described in section 3. The return periods of extreme sea levels are discussed in section 4 . The results of the study are summarized in section 5.

\section{Methodology}

\subsection{Model Description}

\subsubsection{Atmospheric forcing model}

The large pressure drop and the strong wind field associated with a tropical cyclone are its major characteristic features. The variation in the surface pressure produces surge in the deeper part of the bay, but the wind acting on the continental shelf produces the major and disastrous surge. Accordingly, it becomes essential to provide accurate wind and pressure field for forcing the storm surge model.

The pressure field is determined by using the model of Holland (1980) following Flather (1994) as

$$
p=p_{c}+\left(p_{n}-p_{c}\right) \exp \left[-\left(r_{m} / r\right)^{b}\right]
$$

where, $p$ is the atmospheric pressure at radius $r, p_{c}$ is the core pressure, $p_{n}(1010 \mathrm{hPa})$ is the ambient pressure, $r_{m}$ is the radius of maximum winds and $b$ is a scaling parameter that defines the shape of a cyclone with values ranging from 1 to 2.5 . Empirically $b$ is defined (Hubbert et al. 1991; Tang et al. 1997) as

$$
b=1.5+\left(980-p_{c}\right) / 120
$$

where $p_{c}$ is in $\mathrm{hPa}$. The symmetrical, wind profile is estimated (Holland 1980) from the gradient wind equation as given below, from which the components of wind stress, $w_{x}$ and $w_{y}$ are derived

$$
V_{g}=\left\{\frac{b\left(\frac{r_{m}}{r}\right)^{b}\left(p_{n}-p_{c}\right) \exp \left[\left(\frac{r_{m}}{r}\right)^{b}\right]}{\rho_{a}}+\frac{r^{2} f^{2}}{4}\right\}-\frac{r|f|}{2}
$$

w here $\rho_{a}$ is the density of air and $f=2 \omega \sin \varphi$ is the Coriolis parameter, with $\omega$ being the angular speed of the earth's rotation and $\varphi$, the latitude.

\subsubsection{Storm surge model}

The model consists of a system of vertically integrated mass continuity equation and the equation of motion.

$$
\begin{aligned}
\frac{\partial}{\partial}+\frac{\partial U}{\partial x}+\frac{\partial V}{\partial y} & =0 \\
\frac{\partial U}{\partial t}+\frac{\partial}{\partial x}(u U)+\frac{\partial}{\partial y}(v U)-f V= & -g(h+\eta) \frac{\partial \eta}{\partial x}-\frac{1}{\rho} \frac{\partial p}{\partial x}+\frac{\tau_{s x}}{\rho} \\
& -\frac{c_{d} U \sqrt{U^{2}+V^{2}}}{(h+\eta)^{2}}+A \nabla^{2} U
\end{aligned}
$$




$$
\begin{aligned}
\frac{\partial V}{\partial t}+\frac{\partial}{\partial x}(u V)+\frac{\partial}{\partial y}(v V)+f U= & -g(h+\eta) \frac{\partial \eta}{\partial y}-\frac{1}{\rho} \frac{\partial p}{\partial y}+\frac{\tau_{s y}}{\rho} \\
& -\frac{c_{d} V \sqrt{U^{2}+V^{2}}}{(h+\eta)^{2}}+A \nabla^{2} V
\end{aligned}
$$

The terms in the equation of motion (5) and (6) are represented in Cartesian coordinate as the time rate of change and the advective change of the depth mean current, the Coriolis force, the surface pressure gradient, the atmospheric pressure gradient, the wind stress, the bottom stress, and horizontal diffusion term, where $\eta$ elevation of sea surface above an unperturbed level $h(m)$, $u$ zonal component of vertically averaged velocity over the water column of height $(h+\eta)(\mathrm{m} / \mathrm{sec})$, $v$ meridional component of the vertically averaged velocity $(\mathrm{m} / \mathrm{sec})$,

$U=u(h+\eta)$ and $V=v(h+\eta)$ the transports $\left(\mathrm{m}^{2} / \mathrm{sec}\right)$,

f Coriolis parameter $\left(\sec ^{-1}\right)$,

$g$ acceleration due to gravity $\left(\mathrm{m} / \mathrm{sec}^{2}\right)$,

$p$ atmospheric pressure on the sea surface $(h P a)$,

$\rho$ density of sea water assumed to be uniform $\left(\mathrm{kg} / \mathrm{m}^{3}\right)$,

$c_{d}$ bottom drag coefficient (-),

$A$ coefficient of horizontal diffusion of momentum $\left(\mathrm{m}^{2} \mathrm{sec}^{-1}\right)$,

$\bar{\tau}$ surface stress $\left(N / m^{2}\right)$ parameterized as a quadratic of the surface wind velocity $(\bar{W})$ is given as

$$
\bar{\tau}=k \rho_{a} \bar{W}|\bar{W}| ; \quad \bar{W}=\sqrt{w_{x}^{2}+w_{y}^{2}}
$$

where $k$ is the surface drag coefficient and $\rho_{\boldsymbol{a}}$ is the air density.

\subsection{Application of Cyclone and Storm Surge model to the Bay of Bengal}

The inputs required for the generation of cyclone, using Holland model, are the radius of maximum winds, core pressure and the position of the core of the cyclone. Holland (1980, Table

2) showed that the mean errors and maximum errors associated with pressure obtained using Eq.

(1) decreases with increase in radius of maximum winds and has minimal value at $100 \mathrm{~km}$ and 40 -

$60 \mathrm{~km}$. We experimented with different radii of maximum wind and observed that defining $50 \mathrm{~km}$ as the radius of maximum winds in the cyclone model of Holland gave a more realistic surge simulation results.

For the present work, we used a set of 136 low pressure systems (LPS) which were identified and documented in National Institute of Oceanography (2004) by examining the hourly tide gauge data of 27 years (1974-2000) at Paradip, Visakhapatnam and Chennai for storm surge events and identifying the associated meteorological events based on the information from the Indian Daily Weather Report and Mausam, published by the India Meteorological Department. Among the 136 LPS events identified, 30 were depressions (D), 41 deep depressions (DD), 26 cyclonic storms (CS), and 37 severe cyclonic storms (SCS). The report gave a detailed account of the position and the pressure of the cyclone core for each LPS event at each day of its development till the landfall 
for the events identified during 1974-1988. The information about the cyclone tracks for the events that occurred during 1989-2000 were available in-house, a brief summary of which has been provided in the report. Figure 1 presents the tracks of all the 136 events that formed in Bay of Bengal during the period 1974-2000. The analysis of the tracks of the cyclones shows that events leading to significant high sea levels at a particular location on the coast could be identified in a record from a tide gauge at a nearby different location. The core pressure and the position of the cyclone core, interpolated to every 3 hours, were used in the cyclone model of Holland to derive the pressure and wind field using Eq. (1) and (3) for each grid point and at every time step of the storm surge model.

The numerical storm surge model, developed from the basic code of the vertically integrated tidal model, described in Unnikrishnan et al. (1999), was used to simulate surges along the coast of Bay of Bengal. The hydrodynamic equations (4), (5) and (6) were solved by an explicit finite difference scheme on an Arakawa $\mathrm{C}$ grid of resolution approximately $9 \mathrm{~km}$. The time step chosen was 12 seconds to satisfy the Courant-Friedrichs-Lewy (CFL) criterion. The model domain extended from $1.5^{\circ} \mathrm{N}$ to $23^{\circ} \mathrm{N}$ and $79^{\circ} \mathrm{E}$ to $103^{\circ} \mathrm{E}$ (Figure 1) with open boundaries along $79.8^{\circ} \mathrm{E}$ and $1.5^{\circ} \mathrm{N}$, where a radiation type boundary condition (Heaps 1973) was applied,

$$
\begin{aligned}
& v+\left(\frac{g}{h}\right)^{\frac{1}{2}} \eta=0 \text { at the southern boundary along } 1.5^{\circ} \mathrm{N} \\
& u+\left(\frac{g}{h}\right)^{\frac{1}{2}} \eta=0 \text { at the western boundary along } 79.8^{\circ} \mathrm{E}
\end{aligned}
$$

The coastal boundaries were represented as vertical walls made of stair steps across which the normal component of the depth mean current becomes zero. The drag coefficient $k$ in Eq. (7) is given as $k \times 10^{3}=0.8+0.0065 W$ suggested by $W u(1982)$, taking into account the increase in sea surface roughness with increase in wind speed and the bottom drag coefficient $\left(c_{d}\right)$ was taken as 0.0025 after performing several numerical experiments. Unnikrishnan et al. $(2006,2011)$ used a similar code for the simulation of surges driven by the wind field derived from a regional climate model, HadRM2.

Accurate bathymetry of the bay is very essential to get good surge simulations as most of the coastal region bordering Bay of Bengal, especially the northern bay, is very shallow and characterized by sudden change in depth contours which can affect the surge heights considerably. Hence, the bathymetry data for the present work was obtained from one of our recent works (Sindhu et al. 2007) in which improved shelf bathymetry for the Indian Ocean was prepared http://www.nio.org/data_info/bathymetry/modified-etopo.htm) by digitizing the depth contours and sounding depths less than $200 \mathrm{~m}$ from the hydrographic charts published by the Naval Hydrographic Office, India and merging them with the ETOPO-5 datasets through appropriate blending techniques. The work was carried out for creating a better and more accurate bathymetric dataset than ETOPO-5, but with the same resolution as that of the storm surge model.

The storm surge model was forced simultaneously with tides and meteorological forcing. The 
tidal forcing was included in the storm surge model itself, rather than adding the individual tidal model output and the surge model output, in order to take into account the non-linear interaction between tides and surges. The tidal elevations at the open boundary were extracted from the output of a global tidal model developed at Grenoble (version FES2004) (Lyard et al. 2006). Therefore, the storm surge simulation gave the total sea level and the depth mean current due to combined effect of tide and meteorological forcing as output. In order to compute the storm surge component of total sea level, we carried out the simulation of the storm surge model with tidal forcing alone and subtracted the resulting tidal elevation from the total sea level. The storm surge model was run for 4 days prior to the first day of cyclone formation for all the events for spin-up.

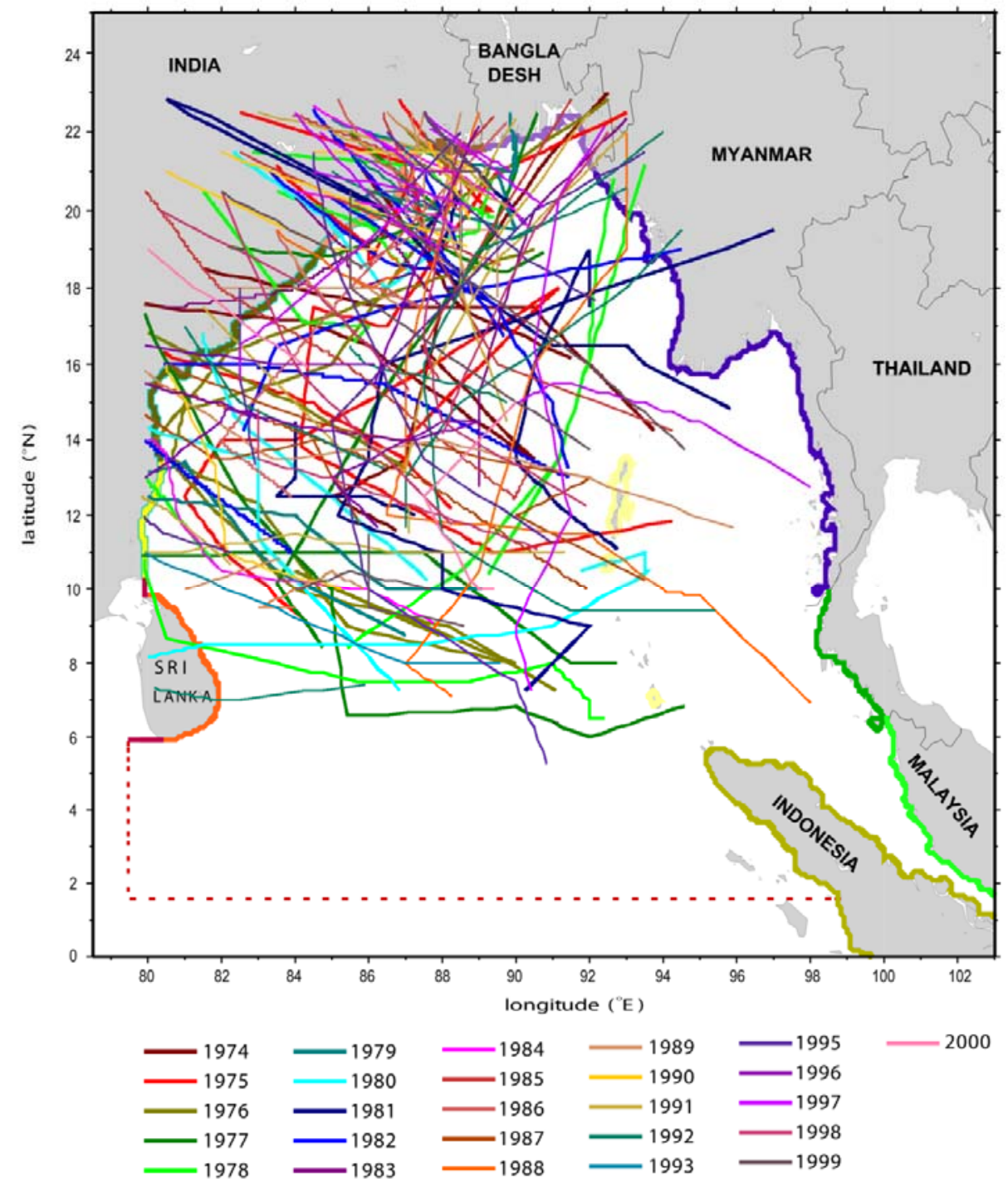

Figure $1 \quad$ The tracks of 136 LPS that developed in the Bay of Bengal during the last 27 years from 1974 to 2000. The tracks of the events occurring in each of 27 years have been differentiated with different colors. 


\section{$3 \quad$ Numerical experiments}

The model results were validated by comparing the simulated level defined at the grid closest to tide gauge location with the observed hourly tide gauge data available during 1974-2000 The surge component of the tide gauge data was extracted by Unnikrishnan et al. (2004). But the spectral analysis of the time series of observed total sea level as well as the surge level showed annual peaks and some higher frequency peaks, so we applied a band pass filter to them in order to carry out the validation. This filter removed the effect of annual variability as well as the high frequency winds and seiches that are not represented by the surge model. Though the simulation of storm surges was carried out for 136 LPS events that occurred in the past 27 years, we are showing the results for some cyclones that crossed Paradip, Visakhapatnam, or Chennai, whose tracks are shown in the Figure 2.

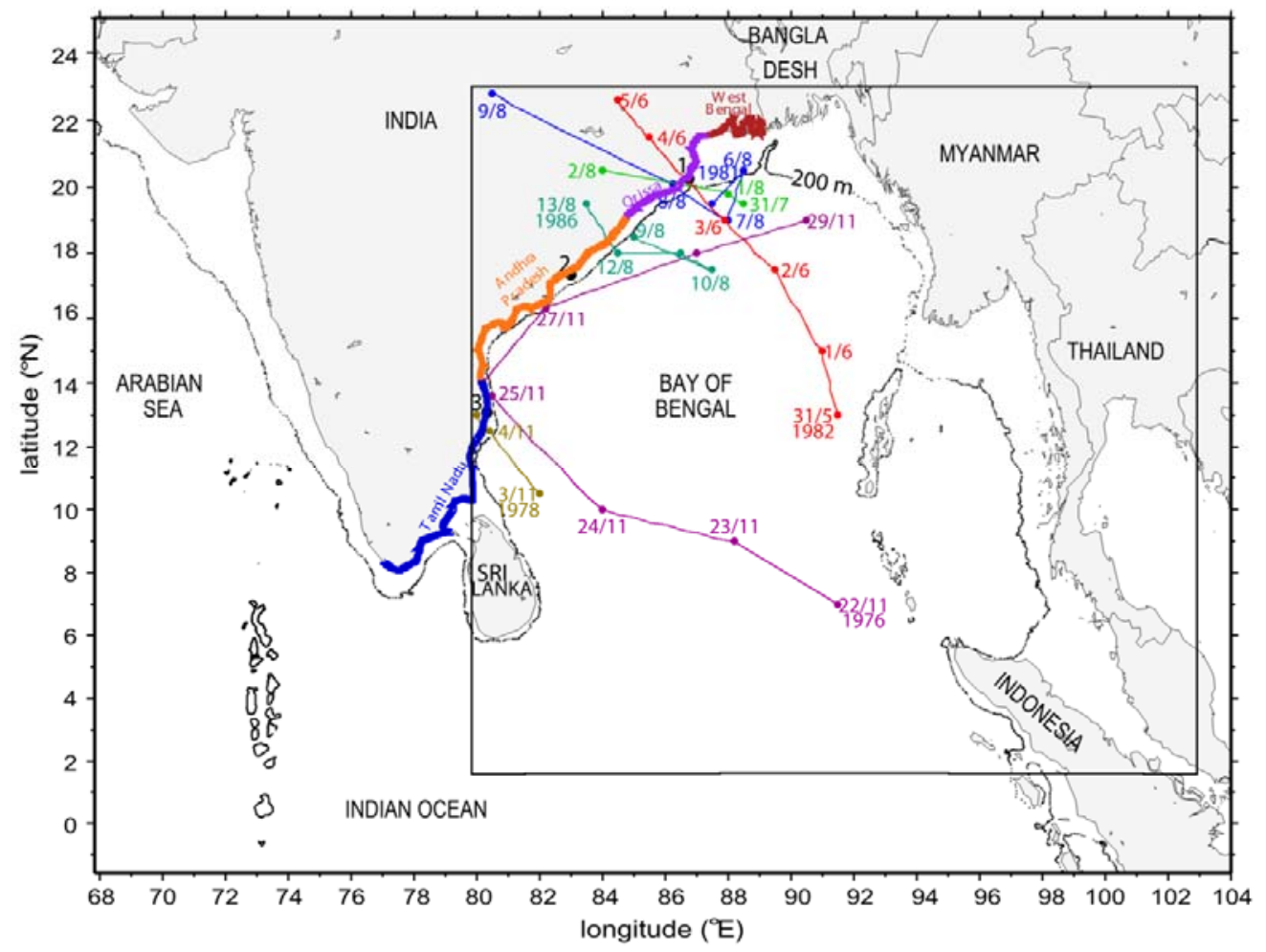

Figure 2 The box in the map shows the model domain. The coastline of Indian statesTamil Nadu, Andhra Pradesh, Orissa, and West Bengal is highlighted. The tracks of the cyclones that caused storm surges at Paradip (marked as 1), Visakhapatnam (marked as 2) and Chennai (marked as 3) are also shown.

\subsection{The surge of 7 August 1981 at Paradip}

A low pressure system was formed over north western Bay of Bengal on 5 August 1981 and after meandering towards north for a day, it recurved, intensified into a cyclonic storm, and finally crossed the coast of Orissa close to and north of Puri on the morning of 8 August with a core pressure of approximately $982 \mathrm{hPa}$. The observed core pressure and position at each day were interpolated to 3 hours and then used in the cyclone model of Holland to derive the wind and pressure field which constituted the major forcing of the storm surge model. The storm surge 
simulation was carried out from 0000 UTC 1 August to 0000 UTC 9 August 1981. Initially, the model was driven only by tidal forcing until the meteorological forcing was introduced from 0000 UTC 5 August. The model simulation using tidal forcing alone was also carried out for the same period, so that the surge component could be derived. Figure $3 \mathrm{a}$ shows the simulated and the filtered observed total sea level with respect to mean sea level at Paradip during the landfall. Figure 3a shows that the simulated peak total sea level of $2.5 \mathrm{~m}$ agrees well with the peak filtered observed sea level of $2.35 \mathrm{~m}$. The simulated surge at Paradip re ached as high as $0.45 \mathrm{~m}$, which is similar to the peak filtered observed surge of $0.43 \mathrm{~m}$.

\subsection{The surge at Paradip due to 3 June 1982 cyclone}

A depression that formed over central Bay of Bengal on 1 June 1982 intensified into a cyclonic storm and then into a severe cyclonic system with its core pressure dropping to $980 \mathrm{hPa}$ on 3 June. The storm crossed the coast of Orissa close to and north of Paradip on 3 June. The model was integrated from 0000 UTC 27 May to 0000 UTC 5 June 1982. The meteorological forcing was included in the model from 0000 UTC 31 May. The model and the filtered observed total sea level are shown in Figure $3 \mathrm{~b}$. The simulated peak sea level $(2.8 \mathrm{~m})$ and the surge elevations $(0.7 \mathrm{~m})$ are in close agreement with that of filtered observed peak levels $(2.9 \mathrm{~m}$ and $0.8 \mathrm{~m})$, respectively.

\subsection{The surge at Paradip due to 1 August 1984 cyclone}

A deep depression with core pressure $992 \mathrm{hPa}$ developed on 1 August 1984 with its core at $19.8^{\circ} \mathrm{N}, 88^{\circ} \mathrm{E}$ from a low-pressure system in the northern bay and crossed the coast of Orissa between Puri and Paradip on 1 August. The surge model simulation was carried out from 0000 UTC 27 July to 0000 UTC 2 August 1984 with meteorological forcing from 0000 UTC 31 July. Figure $3 \mathrm{c}$ shows a good agreement between the simulated and the filtered observed sea level with peak values of $3.05 \mathrm{~m}$ and $3.0 \mathrm{~m}$ respectively. Model simulation shows a peak surge of $0.33 \mathrm{~m}$ at Paradip, which is in close agreement with the filtered observed surge of $0.4 \mathrm{~m}$.

\subsection{The surge at Visakhapatnam due to 25 November 1976 cyclone}

A low pressure area which formed over southern Bay of Bengal on 22 November 1976, moved north west, steadily intensified into a cyclonic storm that skirted the coast of Andhra Pradesh up to 27 November and then finally moved north eastwards to the coast of Arakan weakening into deep depression on 30 November morning. The storm surge simulation was started from rest on 0000 UTC 18 November 1976 with the tidal forcing alone and then from 0000 UTC 22 November, the model was driven by tidal forcing as well as the meteorological forcing. From Figure $3 \mathrm{~d}$, it can be seen that the simulated and the filtered observed sea level matches well with each other with approximately same peak value of $1.6 \mathrm{~m}$. The simulated maximum surge component $(0.25 \mathrm{~m})$ matches with the filtered observed maximum surge component $(0.22 \mathrm{~m})$.

\subsection{The surge at Visakhapatnam due to 12 August 1986 cyclone}

A deep depression (core pressure less than $992 \mathrm{hPa}$ ) that developed from a low-pressure system over northwest Bay of Bengal crossed the coast of northern Andhra Pradesh near Kalingapatnam 
in the night of 12 August 1986. The lowest pressure recorded was $985 \mathrm{hPa}$ at Kalingapatnam. Initially, the tidal forcing drove the surge model from 0000 UTC 5 August to 0000 UTC 8 August and thereafter the meteorological forcing was also introduced. The simulated peak $(1.65 \mathrm{~m})$ and the filtered observed peak $(1.8 \mathrm{~m})$ sea level match well as can be seen from Figure $3 \mathrm{e}$. The simulated maximum surge component is $0.1 \mathrm{~m}$ less than the filtered observed maximum surge component.

\subsection{The surge at Chennai due to 4 November 1978 cyclone}

A deep depression with a core pressure of $1002 \mathrm{hPa}$ crossed the coast of Tamil Nadu around noon of 4 November 1978 near Cuddalore, weakened into a depression and entered into Arabian Sea on 5 November. The model was allowed to spin up by forcing with tides alone for four days prior to 0000 UTC 3 November, when the meteorological force was introduced in the model. According to observations, Chennai is affected by a peak surge of $0.2 \mathrm{~m}$ and thereby a maximum total sea level of $1.2 \mathrm{~m}$ (Figure $3 \mathrm{f}$ ) whereas the model simulation shows a peak total sea level of $1.3 \mathrm{~m}$ with a maximum surge component of $0.3 \mathrm{~m}$.

The time series plot of filtered observed and simulated elevations (Figure 3) shows the importance of the timing of the surge occurrence. Though the cyclone that hit Paradip on 3 June 1982 was more intense than that of 1 August 1984, leading to a higher surge elevation but the total sea level associated with the former event was much less as compared to that of the latter event. The reason is that the peak surge associated with 1 August cyclone occurred at the time of high tide at Paradip. Had the peak surge due to 3 June 1982 cyclone occurred 3-4 hours later, the resulting total sea level and damage would have been much higher. Thus it is very important for the forecasters to know the tidal condition of an area and the time of the occurrence of the peak surge during a cyclone event in order to issue a warning. Figure 3 and the error statistics (Table 1) for the above events indicate that the model can reproduce the observations reasonably well. We

could, thereby, use the model results for the analysis of extreme events in regions where long period observations do not exist. 

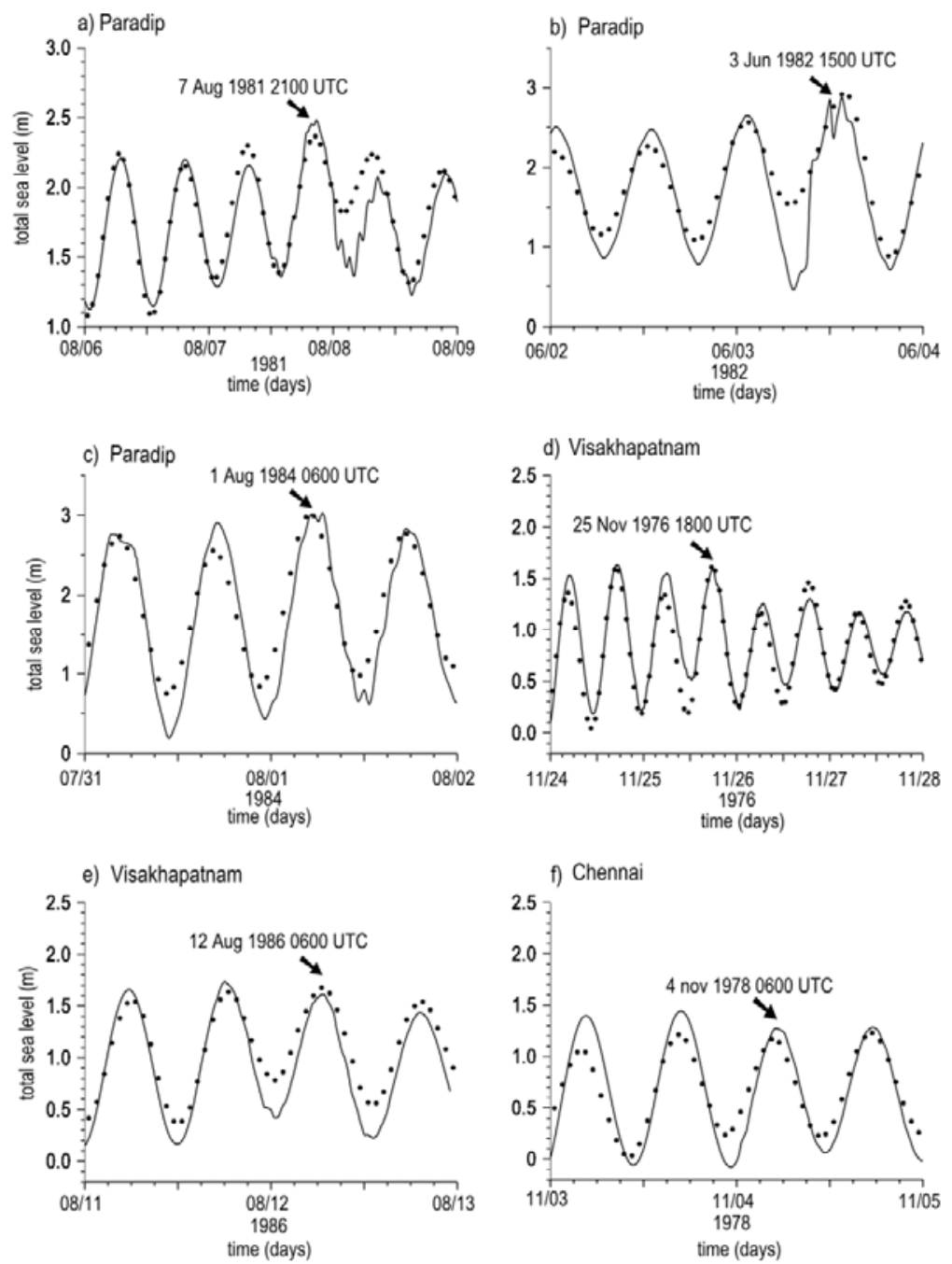

Figure $3 \quad$ Comparison of the time series of simulated total sea level (continuous line) and observed total sea level (dotted line) for 6 cyclone events, whose tracks are shown in Figure 2. The arrow points to the time at which the peak surge occurred at the mentioned station.

Table $1 \quad$ Error statistics showing the agreement between the modelled and the observed surge component for stations shown in Figure 2.

\begin{tabular}{|l|c|c|c|c|}
\hline \multirow{2}{*}{ cyclone event } & \multicolumn{2}{|c|}{ Standard deviation } & \multirow{2}{*}{$\begin{array}{c}\text { Mean error } \\
\text { (model- } \\
\text { observed) }\end{array}$} & RMS error \\
\cline { 2 - 3 } & $\begin{array}{c}\text { Observed } \\
\text { (filtered surge) }\end{array}$ & $\begin{array}{l}\text { Simulated } \\
\text { surge }\end{array}$ & & \\
\hline Paradip & & & & 0.001 \\
08 Aug 1981 & 0.12 & 0.08 & 0.08 \\
03 Jun 1982 & 0.17 & 0.07 & 0.001 & 0.15 \\
01 Aug 1984 & 0.15 & 0.06 & 0.001 & 0.12 \\
\hline Visakhapatnam & 0.04 & 0.04 & 0.02 & 0.06 \\
25 Nov 1976 & 0.15 & 0.05 & 0.02 & 0.12 \\
12 Aug 1986 & & & & \\
\hline Chennai & 0.06 & 0.07 & 0.04 & 0.05 \\
\hline 04 Nov 1978 & & & & \\
\hline
\end{tabular}




\section{$4 \quad$ Extreme sea level analysis}

The risks associated with extreme events can be assessed from the estimates of return periods and return levels. The return period is defined as the inverse of the exceedence probability of an event. The methods used for the estimation of exceedence probability are the annual maximum method (Jenkinson 1955; Gumbel 1958), joint probability method (JPM) (Pugh and Vassie 1979), revised joint probability method (RJPM) (Tawn and Vassie 1989) and the exceedence probability method (Middleton and Thompson 1986). In the present work, we have used the r-largest annual maxima method introduced by Smith (1986) and described by Tawn (1988) which is an extension of the widely used classical method of annual maximum of Gumbel (1958). This method has been chosen as it allows us to use more than one value of extreme sea levels for each year, thereby allowing more reliable estimates of return periods with less number of years of data. For the rlargest annual maxima method, we used the software prepared in the Proudman Oceanographic Laboratory, UK (D. Blackman, personal communication), in which the annual maxima can be allowed to have any of the three Generalized Extreme Value (GEV) distributions. We used Gumbel distribution (GEV Type I) following Unnikrishnan et al. (2004) as the return periods of extreme events obtained from the present study were validated with the return periods obtained by them. They extracted the annual maxima for the period 1974-1988 from hourly tide gauge data at Paradip, Visakhapatnam and Chennai and showed that the plot of the annual maxima against a function $(-\ln (\ln \mathrm{P}))$ produced a straight line suggesting that the underlying probability distribution is Gumbel with a cumulative distribution function as

$$
G(x ; \alpha, \beta)=\exp \{\exp [-(x-\alpha)]\}
$$

where, $\alpha$ and $\beta$ are the location and the scale parameters respectively. The ' $r$-largest annual maxima' were selected following the criteria suggested by Tawn and Vassie (1989) that ' $r$ ' must be large enough to obtain a reasonable estimate of the parameters and that the values selected should fall in the tail of the distribution. The r-largest maxima approach has been used by Bernier and Thompson (2006); Lowe et al. (2001); Flather et al. (1998); Tsimplis and Blackman (1997) for studying the changes in extreme sea levels due to regional climate change. Bernier et al. (2007) and Marcos et al. (2009) mapped the distribution of extreme sea levels in the Southern Europe and Northwest Atlantic, respectively by applying the r-largest maxima methodology on the available long tide gauge records as well as on the output of a 2-D surge models at locations having poor data.

\subsection{Return periods of extreme events along the east coast of India}

The statistical analysis was carried out on the annual maxima of pressure deficit, simulated total sea level and surge component. For each LPS event in the Bay of Bengal, the surge component maxima were obtained first and then the total sea level maxima were picked up by defining a window width of $48 \mathrm{~h}$ consisting of $24 \mathrm{~h}$ before and $24 \mathrm{~h}$ after the occurrence of peak surge in order to avoid the maxima that may be only due to spring tide. The annual total sea level maxima and the surge maxima were then fitted to Gumbel distribution to obtain the scale and the location parameter and thereby the return period was estimated as the reciprocal of Gumbel cumulative 
distribution function. The estimates obtained in this study were validated by comparing with the return periods obtained by Unnikrishnan et al. (2004). They made the first attempt to estimate the return periods along the east coast of India using observed hourly tide gauge data through the same approach.

McInnes et al (2009) estimated storm surge return levels along the south-eastern coastline of Australia by simulating individually the surge events identified in the tide gauge records for the northern Bass Strait. They performed $r$-largest GEV analyses with $r=2, r=3$ and $r=4$ on the simulated surge heights and selected 2-largest GEV fits to estimate the return levels as it gave smaller uncertainties.

The return period for the total sea level was estimated for 26 stations along the east coast of India using the r-largest annual maxima method. The estimates at Paradip, Visakhapatnam and Chennai are shown in Figure 4. The value of ' $r$ ' changed for each station depending on Tawn and Vassie (1989) criterion; at Paradip ' $\mathrm{r}$ ' varied from 2 in most of years to 3 in some years, at Visakhapatnam 3-4 events were accounted and, at Chennai there were 3 events per year. The values of ' $r$ ' used here were similar to those used by Unnikrishnan et al. (2004). Figure 4, in which the estimated return periods are compared against the available return periods determined from observations, shows a good agreement between the return periods obtained from the simulated and the observed maxima. Table 2 shows the estimated parameters and the standard errors associated with them, obtained while fitting the observed and the simulated annual maxima to Gumbel distribution. The comparison of parameters indicated the good agreement between the observed extreme events and the simulated extreme events, thereby providing the confidence to use simulated maxima for deriving the return periods.

The 26 stations along the east coast of India, at which the return periods and the return levels were estimated, are listed in Table 3. Tsimplis and Blackman (1997) showed that choosing $r$ between 5 and 10 extremes per year for the tide gauge stations in the Aegean and Ionian Seas led to consistent return levels. However, for most of the stations in the present study, it was found that considering $r$ greater than 3 led to inclusion of non-extreme values in the extreme value estimation. Therefore, statistical estimations were done for; one maximum per year $(r=1)$, two maxima per year $(r=2)$ and three maxima per year at each station. The sensitivity of the estimates to the value of ' $r$ ' used in the analysis is demonstrated in Table 3. Though the estimated 5-year and 50-year return simulated surge level showed a decrease (18\% and $25 \%)$, respectively with the increase of the number of maxima taken per year, the standard errors associated with them reduced considerably (37\% and 43\%), respectively, a result of increasing sample size of extreme values and thereby, justifying the use of $r=3$. The statistical analysis was done on the core pressures of annual extreme events, to get the return periods of the $\Delta p\left(p_{n}-p_{c}\right)$ for the Bay of Bengal (Table 4). The 5-year return pressure drop is found to be $43 \mathrm{hPa}$, suggesting the occurrence of cyclonic storms, but the 50-year return pressure drop is $61 \mathrm{hPa}$ which can cause severe cyclonic storms.

The spatial variation of return levels of total sea level along the east coast of India (Figure 6a and Figure 7a) shows an increasing trend towards the head bay, the lowest being at Nagapattinam and the highest being at Sagar Island, which is similar to the trend of the tidal range. However, the return levels of surge component (Figure $6 \mathrm{~b}$ and Figure $7 \mathrm{~b}$ ) show different pattern. Along the coast 
of Orissa, the return levels are smaller in the southern part than those in the northern part with the highest value of $2.6 \mathrm{~m}$ at Chandipur. Chittibabu et al. (2004) obtained a similar trend for the 50year return levels of storm surge maxima along the coast of Orissa and attributed it to the near shore topography and orientation of coastline of the region. Similarly, they found higher return levels at Machilipatnam when compared with other stations along the coast of Andhra Pradesh.

The analysis of Figure $6 \mathrm{~b}$ and Figure $7 \mathrm{~b}$ with respect to Figure 5 highlights that shallow and wide coastal shelves result in larger surges than deep and narrow shelves. The stations along the coast of Tamil Nadu show lower 5-year and 50-year return levels of surge component than other stations due to its narrow shelf and deeper bathymetry. Along the coast of Andhra Pradesh, Machilipatnam, Surya Lanka, Kavali and Gudur are found to be sensitive regions as they show considerably high return levels of surge component due to their shallow bathymetry. The 50-year surge level $(0.8 \mathrm{~m})$ at Surya Lanka is found to be highest along the coast of Andhra Pradesh, which can be attributed to the geometrical configuration of the coastline forming a cove shaped bay at this area. Though Machilipatnam is deeper (-6.1 m) than Surya Lanka (-5.0 m) (Figure 5), the 5year and 50-year return levels $(0.6 \mathrm{~m}$ and $0.3 \mathrm{~m})$, respectively are comparable to those at Surya Lanka and found to be higher than that at Kakinada $(-6.0 \mathrm{~m})$ by $40 \mathrm{~cm}$. The reason for this characteristic features is assessed to be the wide shelf (approx. $100 \mathrm{~km}$ ) as compared to that of Surya Lanka and Kakinada (approx $20 \mathrm{~km}$ and $65 \mathrm{~km}$, respectively as shown in Table 3), which shows the effect of wide shelf on the height of surge component. The effect of orientation of coastline on the height of surge component can be discerned at Kakinada where the return levels are substantially lower by almost $60 \mathrm{~cm}$ than that at Surya Lanka in spite of its much wide shelf (about $65 \mathrm{~km}$ ) and similar bathymetry. The highest return levels for the extreme surges are obtained along the coast of Orissa, especially the northern coast because of its very wide shelf and shallow bathymetry. Chandipur (Figure 6 and Figure 7) is found to be highly prone to extreme events with highest 5-year and 50-year return levels $(1.4 \mathrm{~m}$ and $2.6 \mathrm{~m}$, respectively) followed by Sagar Roads (1.3 m and $2.5 \mathrm{~m}$, respectively) and False Point $(0.8 \mathrm{~m}$ and $1.5 \mathrm{~m}$, respectively). The 50-year return levels at Paradip and Puri are $0.7 \mathrm{~m}$ and $0.6 \mathrm{~m}$, respectively which is relatively high compared to the stations in the southern coast of Orissa as they are characterized by relatively shallower depths (Figure 5) and wider shelf (Table 3). Though the continental shelf at Chilka and Gopalpur $(85 \mathrm{~km})$ are as wide as the shelf at Puri, the return levels at these stations are lower by approximately 10 and $20 \mathrm{~cm}$, respectively due to the deeper depths at these stations.

The variations of the return levels of total water levels at different stations along the east coast of India (Figure 7) are found to be consistent with the nomogram developed by Jain et al. (2010). However the relatively higher estimates obtained by Jain et al (2010) as compared to the present study could be probably due to the inclusion of wave setup and the linear addition of tidal amplitudes to the maximum surge levels.

It is therefore shown that, along the east coast of India, the 5-year and 50-year return levels of surge component are considerably higher at shallow and wide shelf regions such as Gudur, Kavali, Surya Lanka, Machilipatnam, False Point and Chandipur than at deep and narrow shelf regions. Hence accurate bathymetry is a key factor in the model simulation to obtain accurate results, which forms the major advantage of our work. 

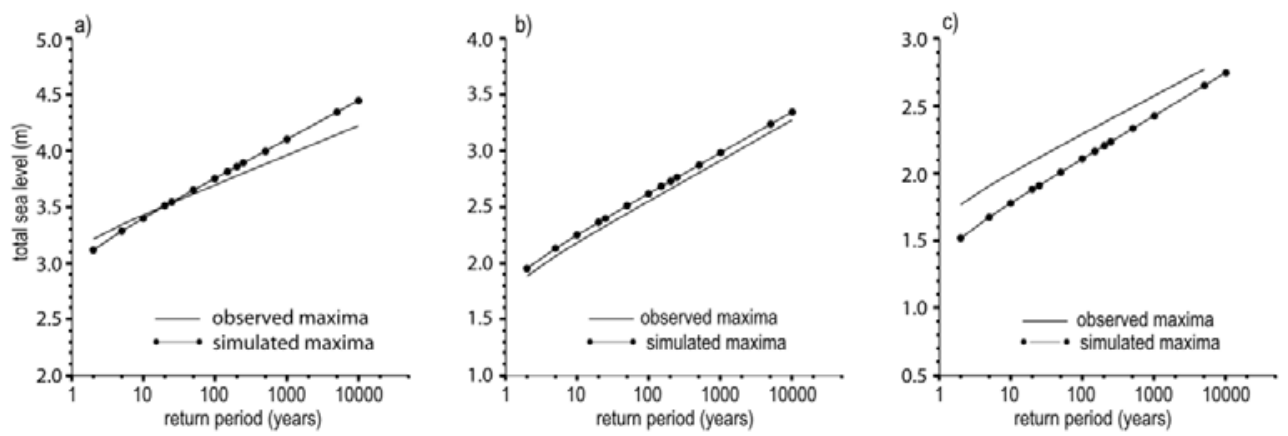

Figure $4 \quad$ Return period estimates obtained from observed annual maxima and simulated annual maxima for a) Paradip, b) Visakhapatnam, and c) Chennai.

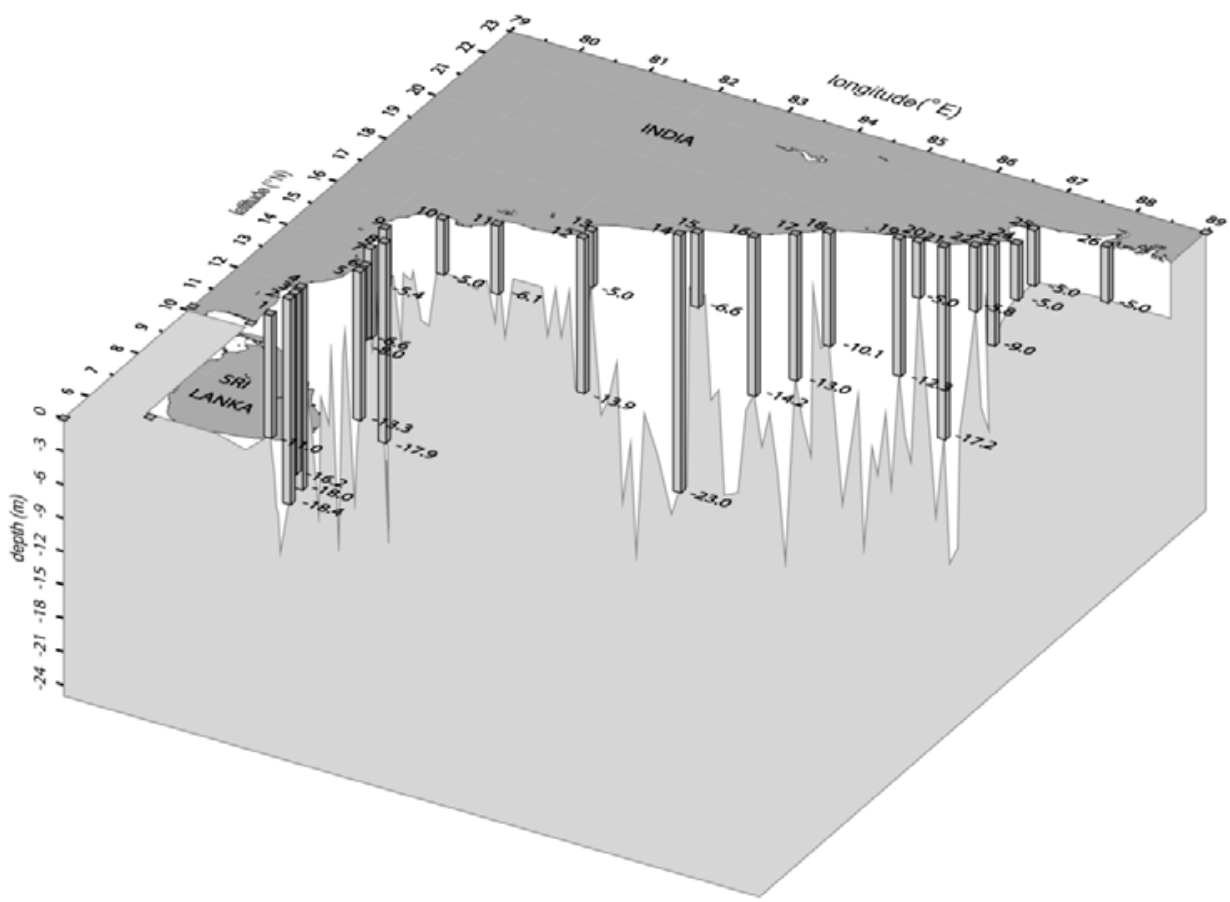

Figure $5 \quad$ A 3D view of the bathymetry along the east coast of India. The shaded portion represents the depth value at each grid nearest to a land point along the east coast of India. The column and the corresponding value show the depth values at 26 stations along the coast. The stations are marked as numbers that correspond to the numbers in Table 3. 

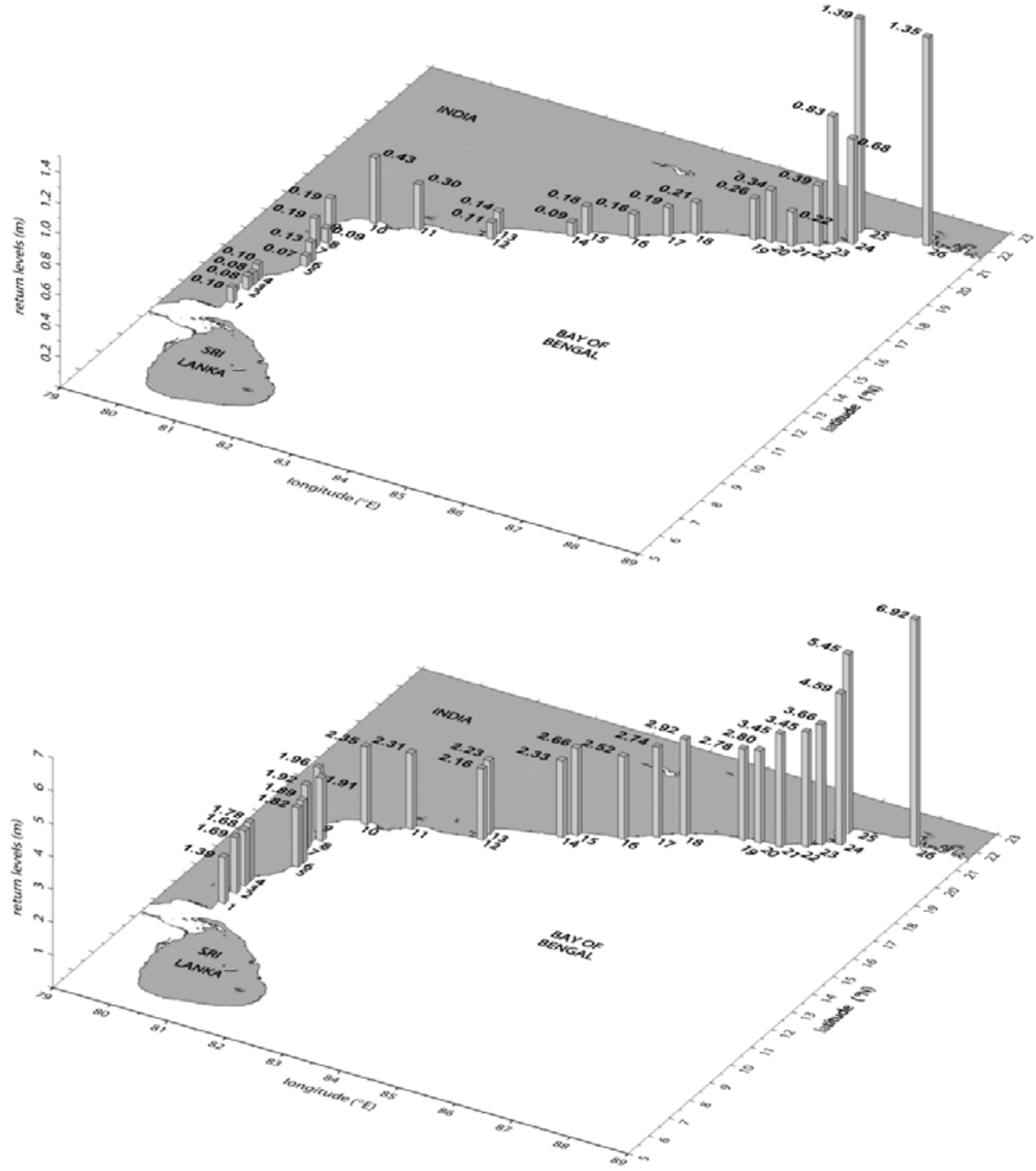

Figure 6 The 5-year return a) total sea level and, b) surge level for 26 stations along the east coast of India. The stations are marked as numbers that correspond to the numbers in Table 3. 

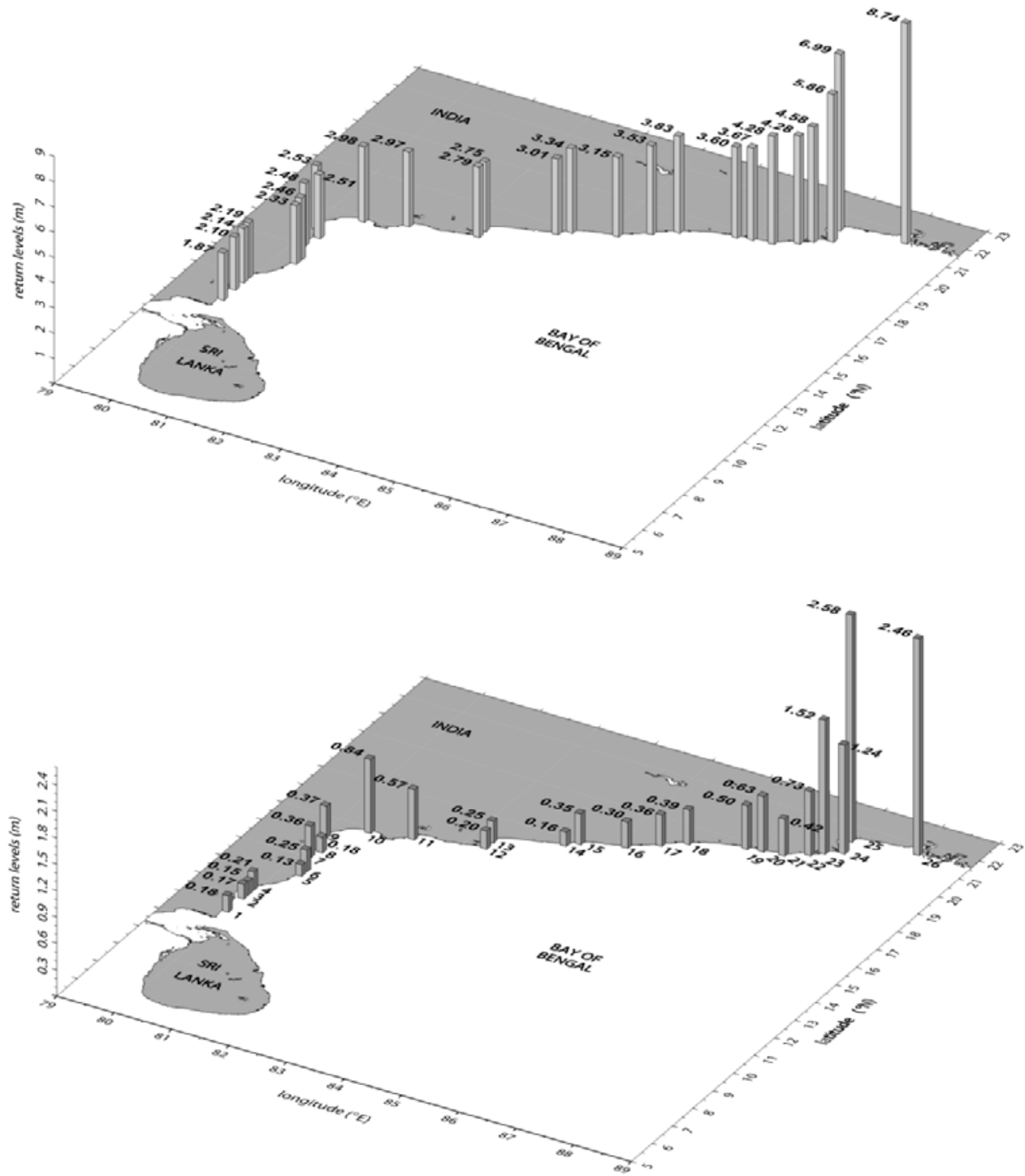

Figure 7 The 50-year return a) total sea level and, b) surge level for 26 stations along the east coast of India. The stations are marked as numbers that correspond to the numbers in Table 3.

Table $2 \quad$ The parameters estimated while fitting the observed maxima and simulated maxima to Gumbel distribution

\begin{tabular}{|l|c|c|c|c|c|c|c|c|}
\hline \multirow{2}{*}{ Stations } & \multicolumn{4}{|c|}{ Parameters for observed maxima } & \multicolumn{4}{c|}{ Parameters for Simulated maxima } \\
\cline { 2 - 9 } & $\alpha$ & $\beta$ & Error in $\alpha$ & Error in $\beta$ & $\alpha$ & $\beta$ & Error in $\alpha$ & Error in $\beta$ \\
\hline \multirow{3}{*}{ Paradip } & 3.17 & 0.11 & 0.03 & 0.02 & 2.97 & 0.32 & 0.05 & 0.03 \\
Visakhapatnam & 1.82 & 0.16 & 0.04 & 0.03 & 1.91 & 0.28 & 0.05 & 0.03 \\
Chennai & 1.72 & 0.12 & 0.04 & 0.03 & 1.49 & 0.21 & 0.03 & 0.02 \\
& & & & & & & & \\
\hline
\end{tabular}


Table 3 The 5-year and the 50-year simulated return levels at 26 stations along the east coast of India, obtained by the analysis of the surge (difference between the simulated total sea level and tidal elevation) maxima through the r-largest annual maxima method. The return levels at each station are given for different ' $r$ ' values, one maximum per year $(r=1)$, two maxima per year $(r=2)$, and 3 maxima per year $(r=3)$. The estimated standard errors associated with the return levels are given in brackets. The shelf width (in $\mathrm{km}$ ) at each station grid point is obtained as the perpendicular distance from the coast to the $200 \mathrm{~m}$ isobath.

\begin{tabular}{|c|c|c|c|c|c|c|c|c|}
\hline \multirow{2}{*}{$\begin{array}{c}\text { St } \\
\text { no. }\end{array}$} & \multirow{2}{*}{ Station Name } & \multirow{2}{*}{$\begin{array}{c}\text { Shelf } \\
\text { Width } \\
(\mathrm{km})\end{array}$} & \multicolumn{3}{|c|}{5 year return surge level } & \multicolumn{3}{|c|}{50 year return surge level } \\
\hline & & & $r=1$ & $r=2$ & $r=3$ & $\mathrm{r}=1$ & $\mathrm{r}=2$ & $\mathrm{r}=3$ \\
\hline 1 & Nagapattinam & 40 & $0.13(0.024)$ & $0.11(0.01)$ & $0.10(0.012)$ & $00.29(0.05)$ & $0.22(0.031)$ & $0.18(0.023)$ \\
\hline 2 & Porto Nova & 20 & $0.10(0.019)$ & $0.09(0.01)$ & $0.08(0.012)$ & $0.22(0.04)$ & $0.19(0.03)$ & $0.17(0.023)$ \\
\hline 3 & Cudallore & 20 & $0.10(0.018)$ & $0.08(0.01)$ & $0.08(0.011)$ & $0.21(0.038)$ & $0.17(0.025)$ & $0.15(0.020)$ \\
\hline 4 & Pondicherry & 30 & $0.13(0.025)$ & $0.11(0.02)$ & $0.10(0.014)$ & $0.30(0.053)$ & $0.24(0.036)$ & $0.21(0.028)$ \\
\hline 5 & Chennai & 30 & $0.08(0.013)$ & $0.07(0.01)$ & $0.07(0.009)$ & $0.16(0.027)$ & $0.14(0.02)$ & $0.13(0.016)$ \\
\hline 6 & Pulicat & 30 & $0.16(0.028)$ & $0.14(0.02)$ & $0.13(0.016)$ & $0.34(0.058)$ & $0.28(0.04)$ & $0.25(0.031)$ \\
\hline 7 & Gudur & 40 & $0.25(0.041)$ & $0.21(0.03)$ & $0.19(0.023)$ & $0.52(0.085)$ & $0.41(0.057)$ & $0.36(0.044)$ \\
\hline 8 & Nellore & 20 & $0.12(0.021)$ & $0.10(0.01)$ & $0.09(0.012)$ & $0.26(0.046)$ & $0.20(0.03)$ & $0.18(0.023)$ \\
\hline 9 & Kavali & 40 & $0.27(0.044)$ & $0.21(0.03)$ & $0.19(0.024)$ & $0.56(0.091)$ & $0.42(0.058)$ & $0.36(0.045)$ \\
\hline 10 & Surya Lanka & 20 & $0.55(0.101)$ & 0.46 & $0.43(0.058)$ & $1.20(0.212)$ & $.144)$ & $0.84(0.113)$ \\
\hline 11 & Machilipatnam & 100 & $0.38(0.066)$ & 0.32 & $0.30(0.0$ & $0.81(0.138)$ & $0.66(0.097)$ & 0.57 \\
\hline 12 & Sacromental Shoal & 30 & $0.13(0.024)$ & $0.11(0.02)$ & $0.11(0.014)$ & $0.28(0.051)$ & $0.23(0.034)$ & $0.20(0.027)$ \\
\hline 13 & Kakinad & 65 & $0.18(0.026)$ & $0.15(0.02)$ & $0.14(0.015)$ & $0.35(0.053)$ & $0.29(0.037)$ & $0.25(0.028)$ \\
\hline 14 & Visakhapatnam & 65 & $0.10(0.014)$ & $0.09(0.01)$ & $0.09(0.010)$ & $0.19(0.03)$ & $0.17(0.023)$ & $0.16(0.020)$ \\
\hline 15 & Bhimunipatnam & 85 & $0.23(0.038)$ & $0.19(0.03)$ & $0.18(0.024)$ & $0.49(0.08)$ & $0.38(0.054)$ & $0.35(0.045)$ \\
\hline 16 & Kalingapatnam & 55 & $0.20(0.034)$ & $0.17(0.02)$ & $0.16(0.02)$ & $0.42(0.07)$ & $0.34(0.047)$ & $0.30(0.037)$ \\
\hline 17 & Barwa & 55 & $0.23(0.037)$ & $0.21(0.03)$ & $0.19(0.023)$ & $0.47(0.076)$ & $0.40(0.055)$ & $0.36(0.044)$ \\
\hline 18 & Gopalpur & 85 & $0.26(0.04)$ & $0.22(0.03)$ & $0.21(0.026)$ & $0.53(0.085)$ & $0.44(0.058)$ & $0.39(0.048)$ \\
\hline 19 & Chilka & 85 & $0.34(0.05)$ & $0.29(0.04)$ & $0.26(0.032)$ & $0.67(0.103)$ & $0.55(0.071)$ & $0.50(0.059)$ \\
\hline 20 & Puri & 85 & $0.39(0.053)$ & $0.37(0.04)$ & $0.34(0.040)$ & $0.76(0.114)$ & $0.70(0.089)$ & $0.63(0.075)$ \\
\hline 21 & Devi Nagar & 55 & $0.27(0.043)$ & $0.24(0.03)$ & $0.22(0.026)$ & $0.56(0.09)$ & $0.46(0.059)$ & $0.42(0.05)$ \\
\hline 22 & Paradip & 175 & $0.47(0.075)$ & $0.41(0.05)$ & $0.40(0.046)$ & $0.97(0.15)$ & $0.78(0.09)$ & $0.73(0.086)$ \\
\hline 23 & False Point & 230 & $0.95(0.14)$ & $0.88(0.10)$ & $0.83(0.09)$ & $1.87(0.28)$ & $1.64(0.202)$ & $1.52(0.17)$ \\
\hline 24 & Shortts Island & 250 & $0.73(0.10)$ & $0.73(0.08)$ & $0.68(0.073)$ & $1.40(0.20)$ & $1.36(0.162)$ & $1.24(0.134)$ \\
\hline 25 & Chandipur & 160 & $1.57(0.23)$ & $1.49(0.19)$ & $1.39(0.16)$ & $3.10(0.415)$ & $2.83(0.36)$ & $2.58(0.298)$ \\
\hline 26 & Sagar Island & 185 & $1.39(0.187)$ & $1.35(0.16)$ & $1.35(0.146)$ & $2.60(0.368)$ & $2.59(0.31)$ & $2.46(0.268)$ \\
\hline
\end{tabular}



used in the estimate of return period, is given as the difference between the core pressure of each cyclone at the time of crossing the coast and the ambient pressure $(1010 \mathrm{hPa})$.

\begin{tabular}{|c|c|}
\hline $\begin{array}{c}\text { Return Period } \\
\text { (years) }\end{array}$ & $\begin{array}{c}\Delta \mathrm{P} \\
(\mathrm{hPa})\end{array}$ \\
\hline 2 & 30.5 \\
5 & 42.7 \\
10 & 50.8 \\
20 & 58.6 \\
25 & 61.1 \\
50 & 68.7 \\
100 & 76.2 \\
\hline
\end{tabular}

\section{Conclusions}

A 2D vertically integrated numerical model was used to simulate storm surge events due to 136 low pressure systems that occurred during the past 27 years (1974-2000) period in the Bay of Bengal. The pressure and position of the core at each day of the cyclone development were used in the cyclone model of Holland to derive the wind and pressure field for each of the 136 events. The storm surge model was forced simultaneously with meteorological forcing and tidal forcing, the latter being extracted from the output of global tidal model. The model was also run with tidal forcing alone so as to compute the surge component as the difference between the elevations obtained from the two simulations. A comparison of the time series of simulated total sea level due to some selective events and the filtered observed sea level, obtained from the tide gauges at Paradip, Visakhapatnam and Chennai, showed a good agreement. Moreover, the simulated peak surge components for the same events were also found to agree with the observed peak surge components. The error analysis of simulated surge component corroborated that the model was able to reproduce the observations well.

One of the reasons attributing to the good accuracy achieved by the model could be the use of improved bathymetry data in the simulation. The bathymetry for the model domain was derived from a newly constructed improved ETOPO- 5 bathymetry dataset which was thoroughly assessed and validated for its accuracy in our previous work. It was proved in our earlier work that the use of this improved bathymetry in tidal circulation model and tsunami propagation model produced more accurate results. The present work, thereby, has the advantage of using a much improved bathymetry dataset for the simulation of storm surges in the Bay of Bengal.

The annual maxima were identified from the simulated total sea level based on the identification of the peak surges and analysed statistically using r-largest annual maxima method to provide the estimates of return periods of extreme events. The return period of extreme events at Paradip, Visakhapatnam, and Chennai obtained from the simulated events agreed fairly well with those obtained from the observed. This agreement showed that the output of the storm surge model simulation could be used to derive extreme event statistics at regions having rare observational 
data. Hence, the 5-year and 50-year return levels were estimated at 26 stations along the east coast of India.

The 5-year and 50-year return levels of total sea level along the east coast of India show a considerable increase from south to north, with highest value at Sagar Island in West Bengal following the trend of tidal range along Indian coast. However, the return levels of surge components are found to vary spatially depending on the bathymetry, width of continental shelf and orientation of coastline of a region. This is the reason for substantially high return levels at Machilipatnam and Surya Lanka, even though the cyclones developed in the Bay of Bengal generally moves north or north-west, producing more extreme events in the northern part.

The simulation of extreme events of 27 years are believed to be long enough to provide reliable estimates of 5-year and 50-year return levels of extreme events along the coast of India. This period includes some of the major super cyclones such as the November 1977 SCS, May 1979 SCS and November 1989 SCS that hit Andhra coast and the SCS that hit coast of Orissa and West Bengal in June 1982, April 1991 and October 1999. Therefore, the present study illustrates that storm surge simulation results can be used to derive the return estimates of extreme events at locations where long period observations of sea level do not exist. The estimated return levels can be used as preliminary estimates for the design of marine structures for the protection of coastal areas.

\section{Acknowledgement}

The first author thanks Council of Scientific and Industrial Research, Government of India for providing a fellowship during the tenure of the work. We thank Dr. Florent Lyard, Laboratoire d'Etude en Geophysique et Oceanographie Spatiale (LEGOS), Toulouse, France for providing the global tidal model (FES2004) results. The hourly tide gauge data were provided by the Geodetic and Research Branch, Survey of India, Dehra Dun. We thank the Proudman Ocanographic Laboratory, UK, for providing the software on extreme sea level analysis. Thanks are extended to Ms Nisha, Mr Subeesh and Mr Nidheesh, who helped us to carry out model simulations. We acknowledge the two anonymous reviewers for providing valuable comments. This is NIO Contribution $\mathrm{xxxx}$.

\section{References}

Bernier N, Thompson KR, Ou J, Ritchie H (2007) Mapping the return periods of extreme sea levels: Allowing for short sea level records, seasonality and climate change. Global Planet. Change 57: 139-150. doi:10.1016/j.gloplacha.2006.11.027

Bernier N, Thompson KR (2006) Predicting the frequency of storm surges and extreme sea levels in the northwest Atlantic. J Geophys Res 111: C10009: doi:10.1029/2005JC003168

Butler A, Heffernan JE, Tawn JA, Flather RA, Horsburgh KJ (2007) Extreme value analysis of decadal variations in storm surge elevations. J of Mar Systems 67: 189-200.

Chittibabu P, Dube SK, Macnabb JB, Murty TS, Rao AD, Mohanty UC, Sinha PC (2004) Mitigation of flooding and cyclone hazard in Orissa, India. Nat Hazards 31: 455-485

Chittibabu P, Dube SK, Sinha PC, Rao AD, Murty TS (2002) Numerical simulation of extreme sea levels for the Tamil Nadu and Sri Lanka Coasts. Mar Geodesy 25: 235-244

Das PK (1972) A prediction model for storm surges in the Bay of Bengal. Nature 239: 211-213.

Dube SK, Jain I, Rao AD, Murty TS (2009) Storm surge modeling for the Bay of Bengal and Arabian Sea. Nat Hazards 51: 3-27. doi: 10.1007/s11069-009-9397-9 
Dube SK, Jain I, Rao AD (2006) Numerical storm surge prediction model for the North Indian Ocean \& the South China Sea. Disaster and Development 1: 47-63

Dube SK, Chittibabu P, Sinha PC, Rao AD, Murty TS (2004) Numerical modeling of storm surges in the head Bay of Bengal using location specific model. Nat Hazards 31:437-453

Dube SK, Chittibabu P, Rao AD, Sinha PC, Murty TS (2000a) Extreme sea levels associated with severe tropical cyclones hitting Orissa coast of India. Mar Geodesy 23: 75-90

Dube SK, Chittibabu P, Rao AD, Sinha PC, Murty TS (2000b) Sea levels and coastal inundation due to tropical cyclones in Indian coastal regions of Andhra and Orissa. Mar Geodesy 23:65-73. doi:10.1080/01490410050030643

Dube SK, Rao AD, Sinha PC, Murty TS, Bahulayan N (1997) Storm surge in the Bay of Bengal and Arabian Sea: The problem and its Prediction. Mausam 48: 283-304

Dube SK, Gaur VK (1995) Real time storm surge prediction system for the Bay of Bengal. Curr Sci 68: 103-113

Dube SK, Sinha PC, Roy GD (1985) The numerical simulation of storm surges along the Bangladesh coast. Dyn Atmos Oceans 9:121-133

Flather RA, Smith JA, Richards JD, Bell C, Blackman DL (1998) Direct estimates of extreme storm surge levels from a 40-year numerical model simulation and from observations. Global Atmos Ocean Syst 6: 165-176

Flather RA (1994) A storm surge prediction model for the northern Bay of Bengal with application to the cyclone disaster in April 1991. J Phys Oceanog 24: 172-186

Frank NL, Hussain SA (1971) The deadliest cyclone in history. Bull Amer Met Soc 52(6): 438444

Ghosh SK (1977) Prediction of storm surges on the coast of India. Ind J Meteorol Geophys 28(2): $157-168$

Gumbel EJ (1958) Statistics of Extreme. Columbia Univ Press, New York

Heaps NS (1973) Three-dimensional numerical model for the Irish Sea. Geophy J R Astron Soc 35: $99-120$

Holland GJ (1980) An analytical model of the wind and pressure profiles in hurricanes. Mon Wea Rev 108: 1212-1218

Horsburgh KJ, Wilson C (2007) Tide-surge interaction and its role in the distribution of surge residuals in the North Sea J Geophys Res 12: C08003. doi:10.1029/2006JC004033

Hubbert GD, Holland GJ, Leslie LM, Manton MJ (1991) A real time system for forecasting tropical cyclone storm surges. Wea Forecasting 6: 86-97

Jakobsen F, Azam MH, Ahmed MMZ, Kabir MU (2006) Cyclone storm surge levels along the Bangladeshi coastline in 1876 and 1960-2000. Coastal Engineering Journal 48 (3): 295-307

Jain I, Rao AD, Jitendra V, Dube SK (2010) Computation of expected total water levels along the east coast of India. J of Coastal Res 26(4): 681-687

Jain I, Chittibabu P, Agnihotri N, Dube SK, Sinha PC, Rao AD (2007) Numerical storm surge prediction model for India Pakistan. Nat Hazards 42: 67-73

Jain I, Chittibabu P, Agnihotri N, Dube SK, Sinha PC, Rao AD (2006a) Simulation of storm surges along Myanmar coast using a location specific numerical model. Nat Hazards 39: $71-82$

Jenkinson AF (1955) The frequency distribution of the annual maximum (or minimum) values of meteorological elements. Q J R Meteorol Soc 81: 158-172

Johns B, Rao AD, Dube SK, Sinha PC (1985) Numerical modelling of tide-surge interaction in the Bay of Bengal. Philosophical Transactions of the Royal Society of London A313: 507-535

Johns B, Dube SK, Mohanty UC, Sinha PC (1981) Numerical simulation of the surge generated by the 1977 Andhra cyclone. Q J R Meteorol Soc 107: 919-934

Johns B, Ali A (1980) The numerical modelling of storm surges in the Bay of Bengal. Q J R Meteorol Soc 106: 1-18

Lowe JA, Gregory JM, Flather RA (2001) Changes in the occurrence of storm surges around the United Kingdom under a future climate scenario using a dynamic storm surge model driven by the Hadley Centre climate models. Clim Dyn 18: 179-188

Lyard F, Lefevre F, Letellier T, Francis O (2006) Modelling the global ocean tides: modern insights from FES2004. Ocean Dynamics 56:394-415

Marcos M, Tsimplis MN, Shaw AGP (2009) Sea level extremes in southern Europe. J Geophys Res 114: C01007. doi:10.1029/2008JC004912

McGranahan G, Balk D, Anderson B (2007) The rising tide: assessing the risk of climate change and human settlements in low elevation coastal zones. Environmental and Urbanization 19: $17-27$

McInnes KL, Macadam I, Hubbert GD, Grady JGO (2009) A modelling approach for estimating 
the frequency of sea level extremes and the impact of climate change in southeast Australia. Nat Hazards 51: 115-137

Middleton JF, Thompson KR (1986) Return periods of extreme sea levels from short periods. J Geophys Res 91: 11707-11716

Murty TS, Flather RA, Henry RF (1986) The storm surge problem in the Bay of Bengal. Prog Oceanog 16: 195- 233

National Institute of Oceanography (2004) Extreme sea level variability along the coast of India: A report on scenario, interim report. Joint Indo-UK Programme on Impacts of Clim Change in India, Goa, $\quad$ India: $\quad 230 \quad$ pp (http://drs.nio.org/drs/bitstream/2264/1191/2/NIO TR 6 2004 Vol)

Pugh DT, Vassie JM (1979) Extreme sea levels from tide and surge probabilities. Proceedings of the $16^{\text {th }}$ Coastal Engineering Conference, Hamburg: 911-930, Am Soc of Civ Eng, Reston, $\mathrm{Va}$

Sindhu B, Suresh I, Unnikrishnan AS, Bhatkar NV, Neetu S, Michael GS (2007) Improved bathymetric datasets for the shallow water regions in the Indian Ocean. J Earth Syst Sci 116(3): 261-274

Sinha PC, Jain I, Bhardwaj N, Rao AD, Dube SK (2008) Numerical modeling of tide-surge interaction alongOrissa coast of India. Nat Hazards 45:413-427. doi:10.1007/s11069-0079176-4

Sinha PC, Jain I, Dube SK, Rao AD, Agnihotri N (2005) Numerical simulation of storm surge along Myanmar coast using a location specific model. Proceedings of the 14th Biennial Coastal Zone Conference New Orleans, Louisiana, July 17 to 21

Smith RL (1986) Extreme value theory based on r-largest annual events. J Hydrol 86: 27-43

Tang YM, Holloway P, Grimshaw R (1997) A numerical study of the storm surge generated by tropical cyclone Jane. J Phys Oceanog 27: 963-976

Tawn JA, Vassie JM (1989) Extreme sea levels: The joint probability method revisited and revised. Proc Inst Civ Eng 87: 429-442

Tawn JA (1988) An extreme value theory model for dependant observations. J Hydrol 10: 227 250

Tsimplis MN, Blackman D (1997) Extreme sea-level distribution and return periods in the Aegean and the Ionian Seas. Estuarine Coastal Shelf Sci. 44: 79-89. doi:10.1006/ecss.1996.0126.

Unnikrishnan AS, Kumar MRR, Sindhu B (2011) Tropical cyclones in the Bay of Bengal and extreme sea-level projections along the east coast of India in a future climate scenario. Curr Sci 101 (3): 79-83

Unnikrishnan AS, Kumar KR, Fernandes SE, Michael GS, Patwardhan SK (2006) Sea level changes along the Indian coast: Observations and Projections. Curr Sci 90 (3): 362-368

Unnikrishnan AS, Sundar D, Blackman D (2004) Analysis of extreme sea level along the east coast of India. J Geophys Res. 109: C06023, doi:10.1029/2003JC002217

Unnikrishnan AS, Shetye SR, Michael GS (1999) Tidal Propagation in the Gulf of Khambhat, Bombay High, and surrounding areas. Proc Indian Acad Sci 108: 155-177

Wu J (1982) Wind stress over sea surface from breeze to hurricane. J Geophys Res 7 (C12): 9704 9706 